\title{
Effects of Antiarrythmic Drug Lidocaine on Ventricular Electrical Activity. A Computer Modelling Study
}

\author{
$\mathrm{K}_{\text {Cardona }}{ }^{1}, \mathrm{~J} \mathrm{Saiz}^{1}, \mathrm{M}$ Monserrat $^{1}, \mathrm{JM}$ Ferrero $(\mathrm{Jr})^{1}, \mathrm{G} \mathrm{Molto}^{2}$ \\ ${ }^{1}$ Centro de Investigación e Innovación en Bioingeniería, Valencia, Spain \\ ${ }^{2}$ Grupo de Redes y Computación de altas prestaciones, Valencia, Spain
}

\begin{abstract}
Lidocaine is a class Ib antiarrythmic drug that acts blocking the fast sodium current. In this work, a mathematical model of lidocaine effects has been developed. This model has been incorporated to the Luo Rudy model of guinea pig ventricular action potential and the effect of different basic cycle lengths (BCL) and concentrations of drug on the action potential characteristics has been studied.

Our results show that at BCL $300 \mathrm{~ms}$ lidocaine reduces maximum current sodium to $7 \%$ and $39 \%$ for 10 $\mu M$ and $100 \mu M$ respectively. If we increase $B C L$, the blockade is reduced. In addition, lidocaine reduces the maximal upstroke velocity, for BCL 500 ms the inhibition is $0.9 \%, 7 \%$ and $38 \%$ for $1 \mu M, 10 \mu M$ and $100 \mu M$ respectively. This reduction depends on BCL. Conduction velocity is also affected by lidocaine, It is reduced to $4 \%$ and $23 \%$ for $10 \mu \mathrm{M}$ and $100 \mu \mathrm{M}$ respectively (BCL 300 ms); lower concentrations do not affect the conduction velocity.
\end{abstract}

\section{Introduction}

Lidocaine is a class $\mathrm{Ib}$ antiarrhythmic drug, that blocks the sodium channel of the cardiac ventricular cells [1]. It is known that lidocaine induces depression of sodium current $\left(\mathrm{I}_{\mathrm{Na}}\right)$ [2] and of maximal upstroke velocity $\left(\dot{V}_{\max }\right)$ of ventricular action potentials $[3,4]$. The blockade developed by lidocaine is stimulation rate dependent; which is called use dependence, the block is increased when the stimulation frequency is incremented $[5,6]$.

Experiments have shown that most of sodium channels open very briefly and then undergo activation during the first few milliseconds of the action potential or pass directly into the inactivated state. Binding studies provide direct information about binding of the drug to different states of the channel. It was found that the blockade was mainly produced during inactivated state. The inactivated state block was mainly developed slowly over a time frame of several hundred of milliseconds [7].
Lidocaine is used in the treatment of ventricular cardiac arrhythmias and cardiac arrest with ventricular fibrillation, specially with acute ischemia, but it is not useful in the treatment of atrial arrhythmias [8].

Although there are two available methods to study numerically the behaviour of drugs, we choose the Guarded Receptor Theory (GRT) in order to consider apparent shifts in channel inactivation and receptor affinity as the result of gated regulation of the diffusion path between the unbound drug poll abd the channels binding site [9]. Experimental results suggest that variations of peak $\mathrm{I}_{\mathrm{Na}}$ during repetitive stimulation are voltage sensitive shifts in equilibrium between unblocked and blocked channels. The GRT postulated fixed drugreceptor affinity but with limited access to the receptor site. This theory considers the kinetics of channel blocking agents to be composed of two processes: coupling of drug to a binding site and the effect of channel gate conformations on drug access to the binding site [9].

The main objective of the present work is to develop a mathematical model of the sodium channel block by lidocaine in guinea pig ventricular cells and to study its effects on action potential characteristics for different concentrations and basic cycle lengths (BCL).

\section{Methods}

In this work, the mathematical model of the cardiac action potential developed by Luo and Rudy (phase II) was used in order to simulate the guinea pig ventricular action potential. In this model the sodium current is expressed as:

$$
I_{N a}=\bar{g}_{N a} \cdot m^{3} \cdot h \cdot j \cdot\left(V-E_{N a}\right)
$$

Where $\bar{g}_{N a}$ is the maximum conductance, $\mathrm{m}^{3}, \mathrm{~h}$ and $\mathrm{j}$ are channel gates, $\mathrm{V}$ is the membrane potential and $\mathrm{E}_{\mathrm{Na}}$ is the reversal potential [10].

We have used the Guarded Receptor Hypothesis to model the lidocaine effect on sodium channel, where interaction between drug and ion channel can be represented by 
If $b(t)$ represents the fraction of drug-complexed channels, the time-dependent fraction of drug-complexed channels is described by:

$$
\frac{d b}{d t}=k \cdot[\text { Drug }] \cdot(1-b)-l \cdot b
$$

Where $\mathrm{k} \mathrm{y} \mathrm{l}$ are forward and reverse rate constants and [Drug] is the drug concentration.

Early studies of drug revealed that the presence of lidocaine reduces the maximum sodium current when the stimulation frequency was increased, suggesting that the block is use dependent [11]. We suggest the following model (figure 1) of blockade of sodium channel by lidocaine, in accordance with experimental studies that have shown drug-receptor interaction mainly in inactivated state.

We consider that lidocaine is a neutral drug, assuming that the binding is controlled by the activation gate $\left(\mathrm{m}^{3}\right)$, whereas unbinding is independent of membrane voltage, and therefore the drug unbinds in all the states.

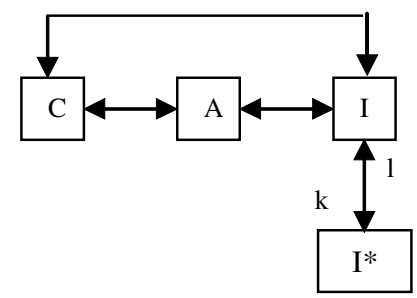

Figure 1. Block diagram for lidocaine in guinea pig ventricular cells.

Subsequently the kinetics is described by:

$$
\frac{d b}{d t}=k \cdot\left(m^{3} \cdot(1-h \cdot j)\right) \cdot[\text { Drug }] \cdot(1-b)-l \cdot b
$$

The response of sodium channel in presence of lidocaine is determined by the stimulation frequency. So with periodic excitation, the time course of each stimulus is shown to be exponential, with a rate and steady state that is linearly dependent on the stimulation frequency. This relationship can be exploited and leads to a simple estimation procedure for the association rates [12]. Consequently we applied this method to the experimental results obtained by Clarkson [13] in guinea pig to find the association and dissociation constants $k=20 \mathrm{~ms}^{-1} \mathrm{M}^{-1}$ and $l=6.3 \times 10^{-4} \mathrm{~ms}^{-1}$, and thereby $K_{d}=31 \times 10^{-6} \mathrm{M}$.

The effect on Na current is described by:

$$
I_{N a}=\bar{g}_{N a} \cdot m^{3} \cdot h \cdot j \cdot(1-b) \cdot\left(V-E_{N a}\right)
$$

\section{Results and Discussion}

In order to study the effect of lidocaine on sodium current, we applied trains of stimuli at different BCLs and concentrations.

Simultaneous recordings of sodium current $\left(\mathrm{I}_{\mathrm{Na}}\right)$, maximal upstroke velocity $\left(\dot{V}_{\max }\right)$, action potential duration $\left(\mathrm{APD}_{90}\right)$ and conduction velocity $(\mathrm{CV})$ are shown for different lidocaine concentrations. Figure 2 shows that, $\mathrm{I}_{\mathrm{Na}}$ peak was $-377 \mu \mathrm{A} / \mu \mathrm{F}$ in normal condition (before application of drug), while in the presence of lidocaine the depression on $\mathrm{I}_{\mathrm{Na}}$ was evident. With a BCL of $300 \mathrm{~ms}$ the $\mathrm{I}_{\mathrm{Na}}$ value was reduced to -347 and $-227 \mu \mathrm{A}$ $/ \mu \mathrm{F}$ for concentrations of $10 \mu \mathrm{M}$ and $100 \mu \mathrm{M}$ lidocaine respectively. This means that the inhibitory effect on sodium current was around $8 \%$ and $39 \%$ respectively.

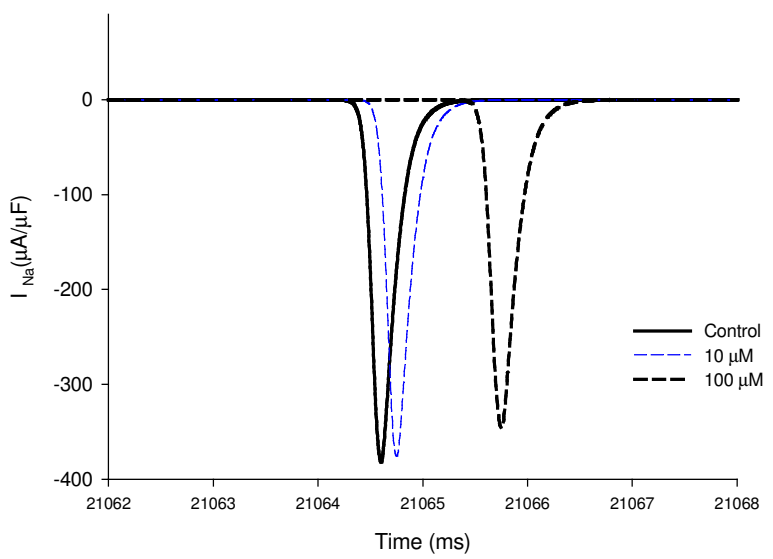

Figure 2. Effect of lidocaine concentration on $\mathrm{I}_{\mathrm{Na}}$ for a BCL $300 \mathrm{~ms}$

At a BCL $1000 \mathrm{~ms}$, the $\mathrm{I}_{\mathrm{Na}}$ was reduced to $2 \%$ and 17 $\%$ for $10 \mu \mathrm{M}$ and $100 \mu \mathrm{M}$ respectively. Our model reproduces the use-dependent property of blocking by lidocaine. Additionally we can observe that the sodium current was triggered later when lidocaine was used than in control conditions.

The effect of lidocaine on $\dot{V}_{\max }$ is illustrated in figure 3. For $1 \mu \mathrm{M}$ the $\dot{V}_{\max }$ was reduced to a $3 \%$ while for 100 $\mu \mathrm{M}$ the reduction was of $22 \%$. 


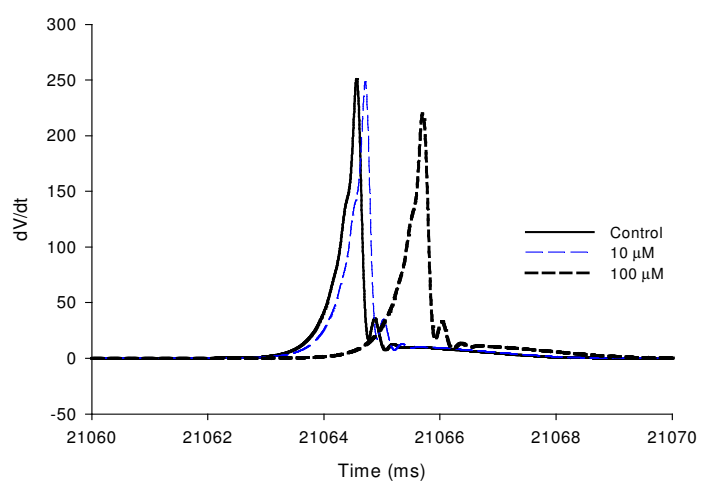

Figure 3. Effects of lidocaine on maximal upstroke velocity of action potential for a BCL $1000 \mathrm{~ms}$.

The differences in the development of use-dependent block on $\dot{V}_{\max }$ to different BCLs and concentrations are shown in table 1.

\begin{tabular}{ccc}
\hline BCL $(\mathrm{ms})$ & $10 \mu \mathrm{M}$ & $100 \mu \mathrm{M}$ \\
\hline 300 & $8.5 \%$ & $47 \%$ \\
500 & $7.5 \%$ & $38 \%$ \\
1000 & $3.2 \%$ & $22 \%$ \\
\hline
\end{tabular}

Table 1 Reduction of $\dot{V}_{\max }$ for different BCLs

These data are similar to different experimental results $[14,15,16]$. In figure 4 experimental data recorded for $\mathrm{BCL}=1000 \mathrm{~ms}(\boldsymbol{\Delta})$ are compared with data obtained using our model $(\bullet)$. Our results confirm the usedependent effect of lidocaine on $\dot{V}_{\max }$.

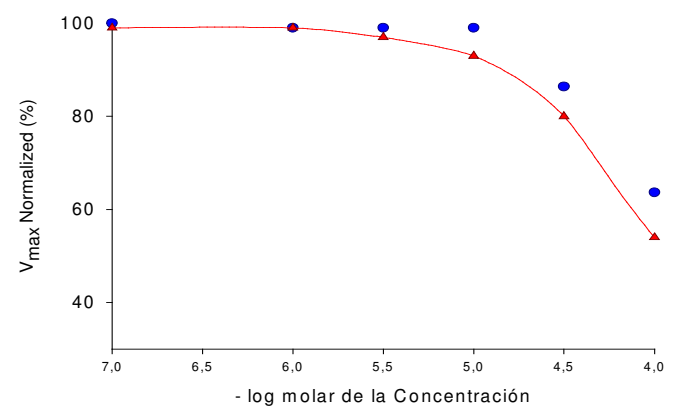

Figure 4. Comparison of the computer predicted values for $\dot{V}_{\text {max }}$ obtained in the presence of lidocaine $(\bullet)$ against experimental data $(\boldsymbol{\Delta})$. For a BCL $1000 \mathrm{~ms}$.

Action potential duration at $90 \%$ repolarization $\left(A P D_{90}\right)$ was unaffected by lidocaine in the tested range of concentrations. In figure 5, we can observe that the highest concentration did not produce a significant change on $\mathrm{APD}_{90}$, likewise, high frequencies did not change this parameter (Table 2). $\mathrm{APD}_{90}$ was prolonged only $2 \%$ for $100 \mu \mathrm{M}$.

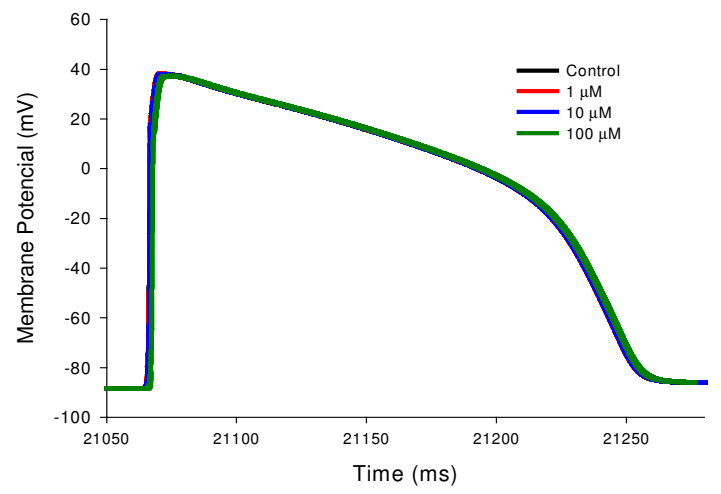

Figure 5. Effect of lidocaine on action potential duration for a BCL $300 \mathrm{~ms}$.

\begin{tabular}{lllll}
\hline \multicolumn{5}{c}{ APD $_{90}$} \\
\hline BCL (ms) & Control & $1 \mu \mathrm{M}$ & $10 \mu \mathrm{M}$ & $100 \mu \mathrm{M}$ \\
300 & 132 & 131 & 132 & 143 \\
500 & 153 & 153.5 & 154 & 159 \\
1000 & 174 & 174 & 174.8 & 177 \\
\hline
\end{tabular}

Table 2. Effects on the duration of action potential

Similarly to $\dot{V}_{\max }$ and $\mathrm{I}_{\mathrm{Na}}$, the conduction velocity $(\mathrm{CV})$ was decremented, when the drug concentration was increased. With a $\mathrm{BCL}$ of $500 \mathrm{~ms}$ the $\mathrm{CV}$ was reduced to $0.41 \mathrm{~m} / \mathrm{s}$ and $0.35 \mathrm{~m} / \mathrm{s}$ for $1 \mu \mathrm{M}$ and $100 \mu \mathrm{M}$ respectively and to $0.41 \mathrm{~m} / \mathrm{s}$ and $0.38 \mathrm{~m} / \mathrm{s}$ for the same concentrations for a BCL of $1000 \mathrm{~ms}$. Figure 6 shows the changes in CV induced by different lidocaine concentrations, expressed as a function of BCL.

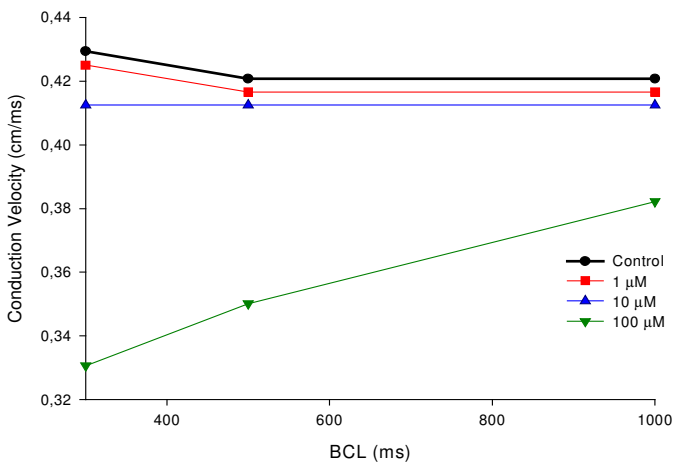

Figure 6. Decrement in conduction velocity induced by different lidocaine concentrations at different BCLs.

\section{Conclusions}

In the present study, we have proposed a model to characterize the behaviour of lidocaine in ventricular 
cells of guinea pig. The model is based on experimental results and takes into account the experimental evidence that shows that the interaction of the drug with the channel occurs in the inactivated state. We can observe that blockade is concentration and frequency dependent.

Lidocaine reduces $\mathrm{I}_{\mathrm{Na}}, \dot{V}_{\max }$ and conduction velocity in high concentration. $\mathrm{APD}_{90}$ is not affected by lidocaine in the tested range of concentrations.

\section{Acknowledgements}

This work was partially supported by the Plan Nacional de Investigación Científica, Desarrollo e Innovación Tecnológica del Ministerio de Educación y Ciencia of Spain (TIC 2001-2686 and TIC 2004-03602). The work of K. Cardona is fully supported by Ministerio de Ciencia y Tecnología (Spain)

\section{References}

[1] Cahalan M D. Modification of sodium channel gating in frog myelinated nerve fibres by Centruroides sculpturatus scorpion venom. J Physiol 1975; (244): 511-534

[2] Bean BP, Cohen CJ, Tsien RW. Lidocaine block of cardiac sodium channels. J Gen Physiol 1983; 81(5):613-642.

[3] Nawada T, Tanaka Y, Hirai S, Hisatome I, Hasegawa J, Kotake $\mathrm{H}$ et al. Evaluation of negative inotropic and antiarrhythmic effects of class 1 antiarrhythmic drugs. Int J Clin Pharmacol Ther 1994; 32(7):347-355.

[4] Matsubara T, Clarkson C, Hondeghem L. Lidocaine blocks open and inactivated cardiac sodium channels. Naunyn Schmiedebergs Arch Pharmacol 1987; 336(2):224-231.

[5] McDonald TV, Courtney KR, Clusin WT. Use-dependent block of single sodium channels by lidocaine in guinea pig ventricular myocytes. Biophys J 1989; 55(6):1261-1266.

[6] Quinteiro RA, Biagetti MO, de Forteza E. Effects of lidocaine on Vmax and conduction velocity in uniform anisotropic canine ventricular muscle: possible role of its binding-rate constants. J Cardiovasc Pharmacol 1990; 15(1):29-36

[7] Gilliam FR, III, Starmer CF, Grant AO. Blockade of rabbit atrial sodium channels by lidocaine. Characterization of continuous and frequency-dependent blocking. Circ Res 1989; 65(3):723-739.
[8] Hine L K, Laird N, Hewitt P, Chalmers T C. Meta-analytic evidence against prophylactic use of lidocaine in acute myocardial infarction. Arch Intern Med 1989; (149): 26942698.

[9] Starmer CF, Grant AO, Strauss HC. Mechanisms of usedependent block of sodium channels in excitable membranes by local anesthetics. Biophys J 1984; 46(1):1527.

[10] Luo CH, Rudy Y. A dynamic model of the cardiac ventricular action potential. I. Simulations of ionic currents and concentration changes. Circ Res 1994; 74(6):10711096.

[11] Starmer CF, Nesterenko VV, Gilliam FR, Grant AO. Use of ionic currents to identify and estimate parameters in models of channel blockade. Am J Physiol 1990; 259(2 Pt 2):H626-H634.

[12] Starmer CF. Characterizing activity-dependent processes with a piecewise exponential model. Biometrics 1988; 44(2):549-559.

[13] Clarkson CW, Hondeghem LM. Evidence for a specific receptor site for lidocaine, quinidine, and bupivacaine associated with cardiac sodium channels in guinea pig ventricular myocardium. Circ Res 1985; 56(4):496-506.

[14] Ehring GR, Moyer JW, Hondeghem LM. Quantitative structure activity studies of antiarrhythmic properties in a series of lidocaine and procainamide derivatives. J Pharmacol Exp Ther 1988; 244(2):479-492.

[15] Mestre M, Djellas Y, Carriot T, Cavero I. Frequencyindependent blockade of cardiac $\mathrm{Na}+$ channels by riluzole: comparison with established anticonvulsants and class I anti-arrhythmics. Fundam Clin Pharmacol 2000; 14(2):107-117.

[16] Sanchez-Chapula J. Electrophysiological interaction between quinidine-lidocaine and quinidine-phenytoin in guinea-pig papillary muscle. Naunyn-Schmiedeberg's Arch Pharmacol 1985, 331: 369-375.

Address for correspondence

Karen Cardona Urrego

Centro de Investigación e Innovación en Bioingeniería

Universidad Politécnica de Valencia

Camino de Vera s/n

46022

Valencia- Spain

E-mail: kacarur1@doctor.upv.es 